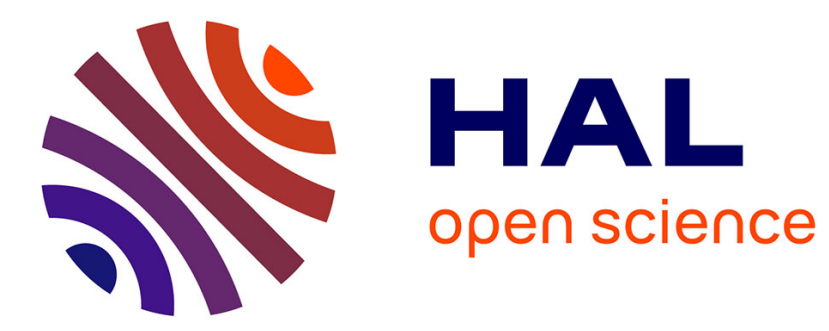

\title{
Oxidative inactivation of NiFeSe hydrogenase
}

Pierre Ceccaldi, Marta Marques, Vincent Fourmond, Inês Cardoso Pereira, Christophe Léger

\section{To cite this version:}

Pierre Ceccaldi, Marta Marques, Vincent Fourmond, Inês Cardoso Pereira, Christophe Léger. Oxidative inactivation of NiFeSe hydrogenase. Chemical Communications, 2015, 10.1039/C5CC05930E . hal-01211493

\section{HAL Id: hal-01211493 \\ https://hal.science/hal-01211493}

Submitted on 5 Oct 2015

HAL is a multi-disciplinary open access archive for the deposit and dissemination of scientific research documents, whether they are published or not. The documents may come from teaching and research institutions in France or abroad, or from public or private research centers.
L'archive ouverte pluridisciplinaire HAL, est destinée au dépôt et à la diffusion de documents scientifiques de niveau recherche, publiés ou non, émanant des établissements d'enseignement et de recherche français ou étrangers, des laboratoires publics ou privés. 


\title{
Oxidative inactivation of NiFeSe hydrogenase ${ }^{\dagger}$
}

\author{
Pierre Ceccaldi, ${ }^{a}$ Marta Marques, ${ }^{b}$ Vincent Fourmond, ${ }^{a}$ Inês Cardoso Pereira, ${ }^{b}$ Christophe Léger $* a$
}

\author{
Received Xth $X X X X X X X X X X 20 X X$, Accepted Xth $X X X X X X X X X 20 X X$ \\ First published on the web Xth $X X X X X X X X X X 200 X$ \\ DOI: $10.1039 / \mathbf{x}$
}

NiFeSe hydrogenases differ from standard NiFe hydrogenases by the replacement of one Ni-bound cysteine with selenocysteine. We used direct electrochemistry to characterize the kinetics of (in)activation of Desulfovibrio vulgaris Hildenborough NiFeSe hydrogenase under various conditions. We conclude that two oxidized inactive forms of the enzyme reductively reactivate at a significant rate, one much faster than the other, at potentials above the $\mathrm{H}^{+} / \mathrm{H}_{2}$ equilibrium potential. Both inactive states can be formed upon either aerobic or anaerobic oxidation, in a "CE" mechanism. We propose a resolution to the paradox that, in contrast with standard NiFe hydrogenases, spectroscopic studies of NiFeSe hydrogenase have not revealed any major signal attributable to $\mathrm{Ni}$ (III) states formed upon reaction with $\mathrm{O}_{2}$, despite the fact that two inactive states are formed under oxidizing conditions.

The enzymes that can reversibly oxidize and produce $\mathrm{H}_{2}$ use inorganic active sites that contain either $\mathrm{Fe}$, or $\mathrm{Ni}$ and $\mathrm{Fe}^{1,2}$. In the latter case, the two metal ions are bridged and attached to the protein by the sulfur atoms of two cysteine residues, and the $\mathrm{Ni}$ is also coordinated by either two additional cysteine residues, or, in the so-called NiFeSe hydrogenases, by one cysteine and one selenocysteine. ${ }^{3}$ Selenium is more acidic and more nucleophilic than sulfur, but it is not clear how this gives selenoproteins particular properties.

All NiFe hydrogenases inactivate under oxidizing conditions. Oxidizing a standard $\mathrm{NiFe}$ hydrogenase produces the so-called Ni-A and Ni-B inactive states, which can be reactivated by reduction, the former more slowly than the latter. Both states are EPR-active $\mathrm{Fe}^{\mathrm{II}} \mathrm{Ni}^{\mathrm{III}}$, and one-electron more oxidized than the most oxidized catalytic intermediate, called Ni-Si. There is a consensus about the Ni bearing a hydroxo ligand in the Ni-B state, but the structure of Ni-A is debated. ${ }^{4,5}$ The situation is even less clear regarding NiFeSe hydrogenases. These enzymes were once believed to be $\mathrm{O}_{2}$

† Electronic Supplementary Information available: figures S1 to S4. See DOI: $10.1039 / \mathrm{x} /$

${ }^{a}$ CNRS, Aix-Marseille Univ., BIP UMR 7281, IMM FR 3479, 31 chemin J. Aiguier, 13402 Marseille Cedex 20, France. Tel: +33 4911645 29; E-mail: christophe.leger@imm.cnrs.fr

${ }^{b}$ Instituto de Tecnologia Qumica e Biolgica Antnio Xavier, Universidade Nova de Lisboa, Oeiras, Portugal resistant because aerobically-prepared samples are essentially EPR-silent and appeared to be active with no lag (in the case of NiFe hydrogenases, a lag phase reveals reductive activation over the course of the assay). However, Armstrong and coworkers use electrochemistry experiments to establish that $\mathrm{O}_{2}$ fully inhibits Desulfomicrobium baculatum (Dbm) NiFeSe hydrogenase, to form two states which are distinguished by the potential at which they undergo rapid reactivation. ${ }^{6}$ The recent finding that the enzyme from Dbm is 6-times more active after anaerobic purification than when it has been exposed to air ${ }^{7}$ is further evidence that $\mathrm{NiFeSe}$ hydrogenases are actually inhibited by $\mathrm{O}_{2}$. In addition, crystallographic studies of Dbm and Desulfovibrio vulgaris Hildenborough (DvH) NiFeSe hydrogenases showed the presence of oxidative modifications both to the active site and to the proximal cluster for the oxidized enzyme purified and crystallized aerobically. ${ }^{7-9}$ Crystallography also revealed multiple conformations and redox states of the (seleno)cystein residues. FTIR was also used to investigate the transformations of the active site of $\mathrm{NiFeSe}$ hydrogenases, with the complication that two conformations of each redox state are detected. ${ }^{10,11}$ Of the four catalytic intermediates of standard NiFe hydrogenases (Ni-Si, Ni-C, Ni-L and Ni-R) ${ }^{1,2}$, only Ni-C and Ni-R have been observed in the seleno-enzyme from DvH. Two oxidized inactive states, Ni-IS and Ni-Ox, are stable in air, EPR-silent, and disappear upon reduction: the former was observed after aerobic purification; the latter was obtained by reductive activation followed by exposure to air. ${ }^{11}$

Using either microbes or enzymes to produce $\mathrm{H}_{2}$ in the presence of $\mathrm{O}_{2}$ is a challenge. In this context, it has been emphasized that NiFeSe hydrogenases, ${ }^{6}$ but also standard $\mathrm{NiFe}$ hydrogenases, ${ }^{12}$ sustain partial activity for $\mathrm{H}_{2}$ production in the presence of small amounts of $\mathrm{O}_{2}$, but only the former appears to resist long exposure to $\mathrm{O}_{2} .{ }^{12}$ This must be related to differences in the kinetics of (an)aerobic (in)activation, which we characterize in this work.

We carried out electrochemical experiments with a soluble recombinant form of the $\mathrm{NiFeSe}$ hydrogenase from $\mathrm{DvH}$, covalently attached ${ }^{13}$ to a pyrolytic graphite edge rotating disc electrode. The cell solution was saturated with $\mathrm{H}_{2}$, in a glovebox filled with $\mathrm{N}_{2}$, and the enzyme-electrode was rotated quickly to minimize substrate depletion near the electrode surface. The catalytic $\mathrm{H}_{2}$ oxidation is proportional to turnover 
rate and electroactive coverage; the latter cannot be measured, but the grafting procedure makes the film very stable.

That DvH NiFeSe hydrogenase reversibly inactivates under anaerobic, oxidizing conditions is clear from the experiment in fig 1 where we show the change in turnover rate (panel B) resulting from the sequence of potential steps shown in panel A. Each step up results in a slow decrease in activity, on the time scale of hundreds of seconds, which reveals an inactivation; a step down reactivates the sample. The process is fully reversible, judging from the values of the current at $t=0$ and $t=1500$ s (horizontal dashed line), and each current relaxation is fairly mono-exponential: this suggests that, under these conditions, the inactivation results from the reversible formation of a single inactive state (however, see below). We used the same model as in ref 14 (section 23 therein) and the open-source program that we recently released (wWw . qsoas . org) to analyse the chronoamperometric data and to measure $k_{i}$ and $k_{a}$, the 1 st order rate constants of inactivation and reactivation. As an example, the red line in fig $1 \mathrm{~B}$ is the best fit of a model that assumes that a single inactive species is formed, adjusting 8 parameters: the 3 values of the current of the fully active enzyme at each of the three potentials, and the values of $k_{i}$ and $k_{a}$ at each potential (forcing $k_{i}=0$ at the lowest potential). We ran and analyzed a number of experiments such as that in fig $1 \mathrm{AB}$, changing the values of the potential steps, to measure the dependence on $E$ of $k_{i}$ and $k_{a}$. The results are shown as empty symbols in fig $1 \mathrm{C}$. The value of $k_{a}$ decreases exponentially as $E$ increases whereas $k_{i}$ is independent of potential.

The (in)activation can also be detected in voltammetric experiments, where the electrode potential is swept upward and downward. Figure 2 shows four cyclic voltammograms (CVs) recorded at a slow scan rate (ranging from 0.3 to $5 \mathrm{mV} / \mathrm{s}$ ), at $50^{\circ} \mathrm{C}, \mathrm{pH} \mathrm{7}$, under one atm. of $\mathrm{H}_{2}$. The arrows indicate the directions of the sweeps. On the sweep upward, the $\mathrm{H}_{2}$ oxidation current increases as a result of the competition between the increase in turnover rate of the active enzyme and the anaerobic inactivation, which decreases the amount of active enzyme. As the potential is reversed, the current decreases (the driving force decreases and the enzyme keeps inactivating), until the potential becomes lower than about $0 \mathrm{~V}$ and the enzyme starts reactivating. The downward trace has a complex shape, with two current peaks (around 0 and $-350 \mathrm{mV}$ at low scan rate) which result from the reactivation of two different inactive species. ${ }^{6}$ The lower the scan rate, the more pronounced the hysteresis. Panel B shows the 1st-order derivatives of the return scans, to emphasize that the positions of the inflexion points on the return scans (the "switch potentials" 15 where the reactivations suddenly occur) shift to lower potential as the scan rate increases, as observed with all hydrogenases. ${ }^{16,17}$ This occurs because the rate of reactivation increases as the potential decreases (see e.g. fig 1C), and

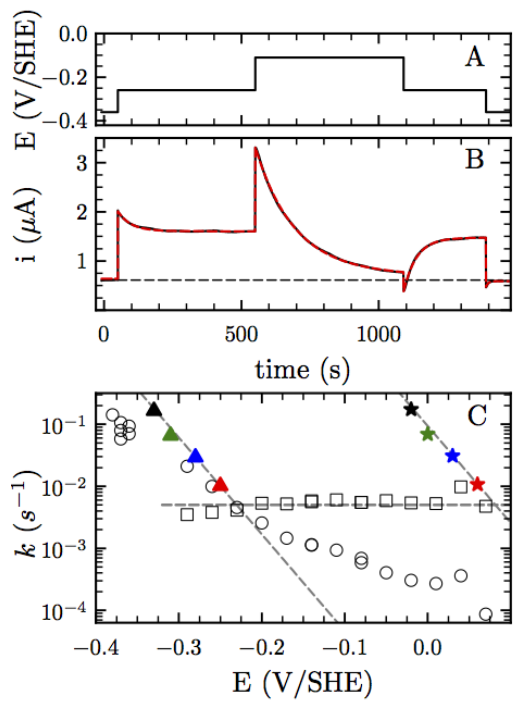

Fig. 1 Oxidative anaerobic inactivation of DvH NiFeSe hydrogenase detected in chronoamperometry (CA) experiments. A. Electrode potential against time. B. Resulting $\mathrm{H}_{2}$ oxidation current, after baseline subtraction (black). The red line is a fit of a model ${ }^{14}$ that assumes that a single inactive species is formed. The best parameters were: $k_{i}=0,4.26 \pm 0.0310^{-3} \mathrm{~s}^{-1}$,

$5.66 \pm 0.0110^{-3} \mathrm{~s}^{-1} ; k_{a}=1.3 \pm 0.0110^{1} \mathrm{~s}^{-1}, 1.67 \pm 0.0110^{-2} \mathrm{~s}^{-1}$, $1.31 \pm 0.0110^{-3} \mathrm{~s}^{-1}$ at $-360,-260,110 \mathrm{mV}$ vs SHE, respectively. C. Activation (empty squares) and inactivation (empty circles) rate constants against electrode potential, deduced from the analysis of a series of CA experiments. The filled symbols are the rate constants of reactivation deduced from fig $2 \mathrm{~B}$.

reactivation significantly proceeds when the reactivation becomes faster than the scan rate $v$ (more rigorously, faster than $v F / R T$, so that the units match). Therefore, the faster the scan rate, the lower the potential where reactivation occurs. It is actually possible to deduce the rate of reactivation at each inflexion point using the following relation: $k_{a}$ (at the inflexion point) $=F \mathrm{v} / R T .{ }^{17}$ Using this equation and the data in fig 2 , we determined the dependence on potential of the rate constants of reactivation of the two different inactive species. The result is shown using a series of triangles and stars in fig $1 \mathrm{C}$, each pair of data points being deduced from a single $\mathrm{CV}$ in fig 2. Since the position of the inflexion points is defined by the kinetics of the reactivation of each species, ${ }^{16,17}$ we refer to the two inactive states as "fast" and "slow" hereafter, to imply that one inactive species reactivates more quickly than the other. Figure 1C shows that the slow (low potential) process (triangles) corresponds to the reactivation that we have characterized above by performing CA experiments (fig 1); the "fast" inactive species was not detected in these experiments because a potential greater than about $100 \mathrm{mV}$ vs SHE is required to trigger its formation. 


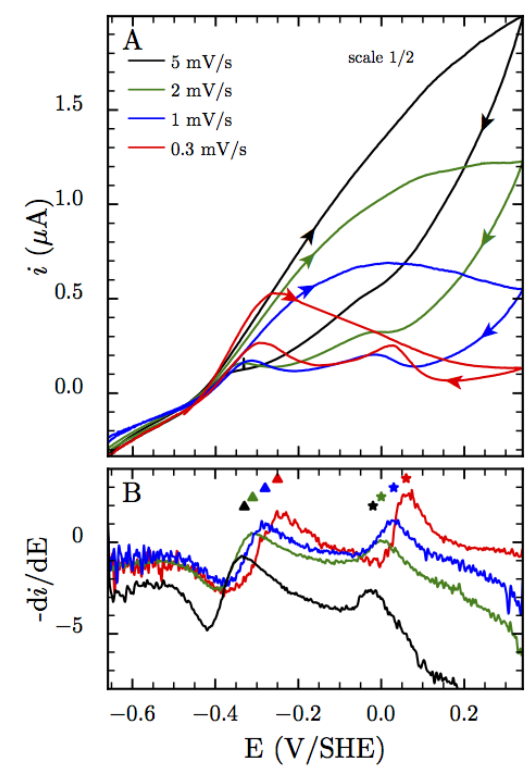

Fig. 2 Figure 2 Oxidative anaerobic inactivation of DvH NiFeSe hydrogenase detected in voltammetric experiments. Panel B shows the 1st order derivative of the return scans shown in panel A (the local maxima mark the "switch potentials". $\mathrm{pH} 7.0,1$ bar $\mathrm{H}_{2}, \mathrm{~T}=$ $50^{\circ} \mathrm{C}, 3.5 \mathrm{krpm}$.

The value and dependence on $E$ of the rate of reactivation of the "fast" inactive species in DvH NiFeSe hydrogenase (stars in fig $1 \mathrm{C}$, deduced from fig 2) is the same as that measured in the CA experiments in fig S2Bii of ref 6 with the Dmb enzyme. Only the reactivation of the "fast" species, which occurs at high potential, was discerned in the CVs in fig $2 \mathrm{~B}$ of ref 6, unlike in fig 2 herein; this is because the Dbm anaerobic CVs were recorded at a faster scan rate $(20 \mathrm{mV} / \mathrm{s})^{6}$ than those used in our experiments $(0.3-5 \mathrm{mV} / \mathrm{s}$, fig 2). At a faster scan rate, the inactive species do not accumulate on the shorter time scale of the voltammetry, and as a consequence, the CV becomes featureless. ${ }^{16,17}$ With the enzyme from Dbm, the "low potential" reactivation peak was observed only in experiments where the enzyme had been inactivated by $\mathrm{O}_{2}$, but in CVs recorded at $1 \mathrm{mV} / \mathrm{s}$ (fig $3 \mathrm{~A}$ in ref 6 ). It was concluded that the "low potential" species (the inactive species that reactivates slowly) is formed only upon reaction with $\mathrm{O}_{2}$. However, the experiments in fig 2 herein and the control experiments in fig $\mathrm{S} 1 \dagger$ clearly show that both inactive species in $\mathrm{DvH}$ NiFeSe hydrogenase can be formed under either aerobic or anaerobic oxidizing conditions; this is like the Ni-A and Ni-B states of standards NiFe hydrogenases. ${ }^{4}$

The sharp decrease in current observed at about $0 \mathrm{~V}$, on the downward scan recorded at $0.3 \mathrm{mV} / \mathrm{s}$ in Fig 2 (red trace) suggests that the enzyme inactivates as the potential is made more negative, which is surprising considering that hydrogenases

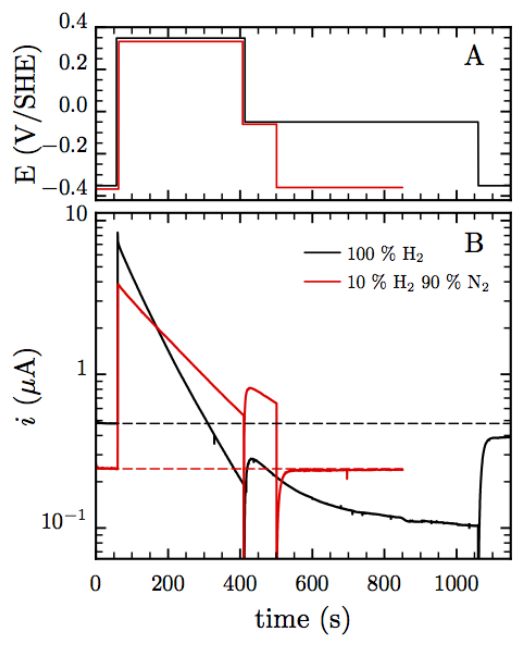

Fig. 3 Transient reactivation after inactivation at $340 \mathrm{mV} / \mathrm{SHE}$. Panel A. Electrode potential as function of time. panel B. Resulting catalytic current (after subtraction of the capacitive current) under $100 \%$ (black line) or $10 \%$ (red line) $\mathrm{H}_{2}$. At $t=400 \mathrm{~s}$, transient reactivation occurs before the enzyme inactivates again. $\mathrm{pH} 7$, $\mathrm{T}=50^{\circ} \mathrm{C}, 3.5 \mathrm{krpm}$

inactivate under oxidizing conditions. The chronoamperometry experiments in figure 3 demonstrate that indeed, the enzyme reactivates in an unprecedented manner when the potential is taken down. The experiments plotted in red and black were carried out under atmospheres of 10 and $100 \% \mathrm{H}_{2}$, respectively. In both experiments, we start from a low potential, where the enzyme is fully active. We step the potential at a very high value $(0.34 \mathrm{~V}$, panel $\mathrm{A})$, where the enzyme inactivates in a 1st order process (hence the exponential decrease in current against time, visible as a straight line in the log-lin plot in panel B). On the downward step at $-0.06 \mathrm{~V}$ (at $t=400 \mathrm{~s}$ ), we observe first an increase then a decrease in current (after $t=420 \mathrm{~s}$ ) that cannot result from film loss. ${ }^{18}$ Therefore, during the step at $-60 \mathrm{mV}$, the enzyme activates and then inactivates. The control experiment in fig $\mathrm{S} 2 \dagger$ shows that the maximal fraction of active enzyme at $-60 \mathrm{mV}$ is about $10 \%$. Complete reactivation is observed after the potential is stepped to its initial value (cf the dashed horizontal lines). We illustrate this totally unprecedented sequence of events using the ternary diagrams in fig $\mathrm{S} 3 . \dagger$

Combining the results in fig $1 \mathrm{C}$ and the observation that the rate of inactivation at very high potential is independent on potential (fig S2A in ref 6), we conclude that both inactive species are reversibly formed, under oxidizing conditions, in a two-step, CE mechanism: a chemical step, C, limits the rate of inactivation, whereas the reactivation is triggered by a reduction, E. The reactivation proceeds along the reverse sequence: reduction followed by chemical transformation. (This is also 
A

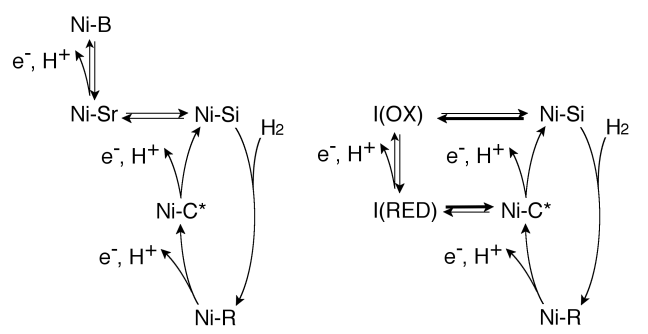

Fig. 4 Oxidative inactivation can result from the formation of a species that is either more oxidized (panel A, standard NiFe Hase) or as oxidized (panel B, NiFeSe Hase) than $\mathrm{Ni}-\mathrm{Si}$, the oxidized catalytic intermediate that undergoes inactivation. Horizontal arrows depict chemical steps, vertical arrows are redox transformations, the more oxidized species being on top. A single pair of inactive species is shown in each case. The Ni-L intermediate ${ }^{2}$ is not shown here.

the case of the Ni-B state of NiFe hydrogenase ${ }^{15-17}$ and the two inactive states of FeFe hydrogenase. ${ }^{19}$ )

At this point, it is not clear if the inactive species that are formed on the time scale of the electrochemical experiments correspond to any of those that have been crystallized before, since the aerobic crystallization process involves long term exposure to oxidizing conditions. Two reversible modifications are detected in the structures: the oxidation of the proximal cluster and the binding of an exogenous $\mathrm{S}$ at the active site.

The lack of any EPR signal arising from an inactive state more oxidized than the most oxidized catalytic intermediate has been bewildering. To resolve this paradox, we note the following: the fact that the enzyme inactivates under oxidative conditions does not imply that the "E" reaction following the " $\mathrm{C}$ " chemical step is an oxidation (as indeed occurs in $\mathrm{NiFe}$ and $\mathrm{FeFe}$ hydrogenases); it merely implies that the inactive species exists in two different redox states, and only the reduced form activates at a significant rate. We show in fig 4 how the inactive form(s) may be connected to the catalytic intermediates in the case of $\mathrm{NiFe}$ (left) and NiFeSe hydrogenase (right). This alternative had actually been considered in a paper of Limoges and Savant (scheme 3 in ref 20), in the very first attempt at modelling the hysteresis in the voltammetry of $\mathrm{NiFe}$ hydrogenase, but not ever since, and not in any paper about NiFeSe hydrogenase.

Surprisingly, the experiments in fig 3 show that the rate of oxidative inactivation at high potential increases when the concentration of $\mathrm{H}_{2}$ increases. The effect is also clear in the experiments shown in fig $\mathrm{S} 4, \dagger$ where we observe that increasing the concentration of $\mathrm{H}_{2}$ while the enzyme is inactivating at high potential causes an increase of both the current and the rate of inactivation. The opposite trend is observed for the Ni-B state of standard hydrogenases, where $\mathrm{H}_{2}$ binding to the catalytically competent, oxidized, Ni-Si state competes with the formation of the Ni-B state. ${ }^{17}$ Regarding NiFeSe hydrogenase, we therefore propose that the high potential inactivation is related to $\mathrm{H}_{2}$ binding. This is reminiscent of the behavior of FeFe hydrogenases, where inactive species are formed under oxidizing anaerobic conditions as a result of the nonproductive binding of hydrogen to the active site H-cluster. ${ }^{19}$ This observation is certainly a clue to design experiments that will help understand the structures of the inactive states of $\mathrm{NiFeSe}$ hydrogenase, and the how the replacement of sulfur by selenium gives the enzyme its peculiar kinetic properties.

\section{References}

1 W. Lubitz, H. Ogata, O. Rüdiger and E. Reijerse, Chem. Rev., 2014, 114, 4081-4148.

2 R. Hidalgo, P. A. Ash, A. J. Healy and K. A. Vincent, Angew. Chem. Int. ed., 2015, 54, 7110-7113.

3 C. S. A. Baltazar, M. C. Marques, C. M. Soares, A. M. DeLacey, I. A. C. Pereira and P. M. Matias, Eur. J. Inorg. Chem., 2011, 2011, 948-962.

4 A. Abou Hamdan, B. Burlat, O. Gutierrez-Sanz, P. Liebgott, C. Baffert, A. de Lacey, M. Rousset, B. Guigliarelli, C. Leger and S. Dementin, Nat. Chem. Biol., 2013, 9, 15-17.

5 A. Volbeda, L. Martin, E. Barbier, O. Gutiérrez-Sanz, A. De Lacey, P.P. Liebgott, S. Dementin, M. Rousset and J. Fontecilla-Camps, J. Biol. Inorg. Chem., 2015, 20, 11-22.

6 A. Parkin, G. Goldet, C. Cavazza, J. C. Fontecilla-Camps and F. A. Armstrong, J. Am. Chem. Soc., 2008, 130, 13410-13416.

7 A. Volbeda, P. Amara, M. Iannello, A. L. De Lacey, C. Cavazza and J. C. C. Fontecilla-Camps, Chem. commun., 2013, 49, 7061-7063.

8 M. C. Marques, R. Coelho, A. L. De Lacey, I. A. Pereira and P. M. Matias, J. mol. biol., 2010, 396, 893-907.

9 M. C. Marques, R. Coelho, I. A. C. Pereira and P. M. Matias, International Journal of Hydrogen Energy, 2013, 38, 8664-8682.

10 J. Riethausen, O. Rüdiger, W. Gärtner, W. Lubitz and H. S. Shafaat, Chembiochem, 2013, 14, 1714-1719.

11 A. L. De Lacey, C. Gutiérrez-Sánchez, V. M. Fernández, I. Pacheco and I. A. Pereira, J. Biol. Inorg. Chem., 2008, 13, 1315-1320.

12 H. S. Shafaat, O. Rüdiger, H. Ogata and W. Lubitz, Biochim. Biophys. Acta, 2013, 1827, 986-1002.

13 O. Rüdiger, J. M. Abad, E. C. Hatchikian, V. M. Fernandez and A. L. De Lacey, J. Am. Chem. Soc., 2005, 127, 16008-16009.

14 J. G. Jacques, B. Burlat, P. Arnoux, M. Sabaty, B. Guigliarelli, C. Léger, D. Pignol and V. Fourmond, Biochim. Biophys. Acta, 1801.

15 A. K. Jones, S. E. Lamle, H. R. Pershad, K. A. Vincent, S. P. J. Albracht and F. A. Armstrong, J. Am. Chem. Soc., 2003, 125, 8505-8514.

16 V. Fourmond, P. Infossi, M.-T. Giudici-Orticoni, P. Bertrand and C. Léger, J. Am. Chem. Soc., 2010, 132, 4848-4857.

17 A. A. Hamdan, P.-P. Liebgott, V. Fourmond, O. Gutiérrez-Sanz, A. L. De Lacey, P. Infossi, M. Rousset, S. Dementin and C. Léger, Proc. Nat. Acad. Sc. USA, 2012, 109, 19916-19921.

18 We rule out the possibility that the decrease in current on the step at $-60 \mathrm{mV}$ results from film loss because on the fourth step, back to the initial potential, the enzyme reactivates and the initial current is nearly entirely recovered, cf the horizontal dashed lines.

19 V. Fourmond, C. Greco, K. Sybirna, C. Baffert, P.-H. H. Wang, P. Ezanno, M. Montefiori, M. Bruschi, I. Meynial-Salles, P. Soucaille, J. Blumberger, H. Bottin, L. De Gioia and C. Léger, Nat. Chem., 2014, 6, 336-342.

20 B. Limoges and J.-M. Savéant, J. Electroanal. Chem., 2004, 562, 43-52. 